\title{
Survival of Medicare Patients After Enrollment in Hospice Programs
}

\section{Citation}

Christakis, Nicholas A. and Jose J. Escarce. 1996. Survival of Medicare patients after enrollment in hospice programs. New England Journal of Medicine 335, no. 3: 172-178. Partially reprinted in Year Book of Family Practice, ed. A.O. Berg. St. Louis, MO: Mosby-Year Book, Inc., 1998.

\section{Published Version}

http://dx.doi.org/10.1056/NEJM199607183350306

\section{Permanent link}

http://nrs.harvard.edu/urn-3:HUL.InstRepos:3710309

\section{Terms of Use}

This article was downloaded from Harvard University's DASH repository, and is made available under the terms and conditions applicable to Other Posted Material, as set forth at http:// nrs.harvard.edu/urn-3:HUL.InstRepos:dash.current.terms-of-use\#LAA

\section{Share Your Story}

The Harvard community has made this article openly available.

Please share how this access benefits you. Submit a story.

\section{Accessibility}




\title{
SURVIVAL OF MEDICARE PATIENTS AFTER ENROLLMENT IN HOSPICE PROGRAMS
}

\author{
Nicholas A. Christakis, M.D., Ph.D., M.P.H., AND José J. Escarce, M.D.
}

\begin{abstract}
Background Each year more than 220,000 Medicare beneficiaries receive care from hospice programs designed to enhance the quality of the end of life. Enrollment requires certification by a physician that the patient has a life expectancy of less than six months. We examined how long before death patients enrolled in hospice programs.
\end{abstract}

Methods Using 1990 Medicare claims data, we analyzed the characteristics and survival of 6451 hospice patients followed for a minimum of 27 months with respect to mortality.

Results The patients' mean age was 76.4 years; 92.4 percent were white. Half the patients were women, and 80.2 percent had cancer of some type. The most common diagnoses were lung cancer (21.4 percent), colorectal cancer (10.5 percent), and prostate cancer (7.4 percent). The median survival after enrollment was only 36 days, and 15.6 percent of the patients died within 7 days. At the other extreme, 14.9 percent of the patients lived longer than six months. Survival varied substantially according to diagnosis, even after adjustment for age and coexisting conditions. The unadjusted survival after enrollment was shortest for those with renal failure, those with leukemia or lymphoma, and those with liver or biliary cancer; it was longest for those with chronic lung disease, those with dementia, and those with breast cancer. Patients at for-profit, larger, outpatient, or newer hospices lived longer after enrollment than those in other types of hospice programs.

Conclusions Most patients who enter hospice care do so late in the course of their terminal illnesses. The timing of enrollment in hospice programs varies substantially with the characteristics of the patients and the hospices. (N Engl J Med 1996;335:172-8.)

(C)1996, Massachusetts Medical Society.

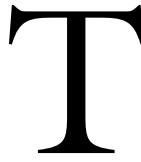

HE primary goal of hospice care is the palliation of patients' physical and mental suffering. Hospice care may offer several advantages over traditional, hospital-based care for people with terminal illnesses. It can be delivered in a patient's home, allowing death to take place at home, ${ }^{1,2}$ and it may optimize the relief of pain, ${ }^{3}$ increase patients' satisfaction, ${ }^{4-6}$ and increase cost ef- fectiveness.7-12 Partly in anticipation of such advantages, Medicare began covering hospice care for its beneficiaries in 1982.13,14 A Medicare beneficiary with a terminal illness who elects hospice care receives noncurative medical and support services, many of which would not otherwise be covered. These services include nursing care; physicians' services; medical appliances; drugs; short-term hospitalization; the services of homemakers and home health aides; physical, occupational, and speech therapy; psychological counseling; and social services. About 80 percent of patients have these services provided in their homes. ${ }^{15}$ In 1994, a total of 221,849 beneficiaries received hospice care at a cost to Medicare of $\$ 1.32$ billion, and the number of beneficiaries receiving hospice care has been growing at an annual rate of 10 to 20 percent (Bureau of Policy Development, Health Care Financing Administration: unpublished data). Medicare beneficiaries make up approximately 80 percent of all patients receiving hospice care in the United States. ${ }^{16}$

Under Medicare regulations, a beneficiary is eligible for coverage of hospice care only if the patient's doctor and the medical director of the hospice certify that the patient is "terminally ill," defined as having a life expectancy of six months or less. ${ }^{17}$ By electing to receive hospice care, the beneficiary waives all rights to Medicare payment for curative treatment of his or her terminal condition. The six-month standard may be difficult, however, for physicians to interpret or apply. ${ }^{18}$ Using a multistate sample, we determined the characteristics of Medicare patients whose life expectancy had been predicted and who had enrolled in hospice programs. We also examined the duration of their survival after enrollment.

From the Section of General Internal Medicine, Department of Medicine, and the Department of Sociology, University of Chicago, Chicago (N.A.C.); and the Division of General Internal Medicine, Department of Medicine, and the Leonard Davis Institute of Health Economics, University of Pennsylvania, Philadelphia (J.J.E.). Address reprint requests to Dr. Christakis at the Section of General Internal Medicine, University of Chicago Medical Center, 5841 S. Maryland Ave., MC 6098, Chicago, IL 60637. 


\section{METHODS}

\section{Sources of Data}

From the Health Care Financing Administration, we obtained the Standard Analytic File (SAF) for all Medicare patients admitted to hospice programs during 1990 in California, Florida, New York, Pennsylvania, and Texas. These five states accounted for 27 percent of all Medicare-certified hospice programs (320 providers) and approximately 36 percent of all Medicare beneficiaries in 1990. Additional data were obtained from 1990 Medicare Provider Analysis and Review (MEDPAR) files; vital-status files containing dates of death for beneficiaries who had died; and Provider of Services (POS) files describing the hospices.

\section{The Cohort}

The study cohort consisted of the 6451 adults who were enrolled for the first time in their lives in a hospice program (covered by Medicare) between October 1 and December 31, 1990, in the five states. Using the vital-status files, we obtained followup with respect to mortality through April 1, 1993 (a minimum of 27 months of follow-up from the date of enrollment). On this date, only 273 patients ( 4.2 percent of the cohort) were still alive. For each patient in the cohort, we also obtained data regarding prior inpatient hospitalizations and calculated a score on the Charlson comorbidity index ${ }^{19}$ using information from the MEDPAR files about hospitalizations during the 270 days before admission to a hospice. Finally, we obtained information on the characteristics of the hospice program from the POS file.

\section{Statistical Analysis}

We estimated survival in the cohort with the Kaplan-Meier method. ${ }^{20}$ In assessing the relation between diagnosis and the length of survival after enrollment in a hospice, we used Tukey box plots, which show the median, interquartile range (the range from the 25 th to the 75 th percentile for values in the cohort), and "whiskers" for each variable (whiskers are 1.5 times the interquartile range and spread out from the first and third quartiles; by definition, they cannot extend beyond the smallest or largest observed value).21

We performed Cox regression analyses to assess the association between diagnosis and survival while controlling for potential confounders and to examine the importance of other variables. In Cox regression, the association between a variable and survival is expressed as a hazard rate or risk ratio, similar to an odds ratio. ${ }^{22}$ In this study a risk ratio greater than 1.0 was associated with a higher risk of death and therefore with a shorter survival after enrollment in a hospice, and a ratio less than 1.0 indicated a lower risk of death and longer survival.

The dependent variable in our analyses was the length of survival in days. The independent variables included the patient's age, sex, race, and principal diagnosis (defined as the condition reported in the SAF to be the cause of the patient's admission, indicated by codes from the International Classification of Diseases, 9th Revision, Clinical Modification ${ }^{23}$ ). We grouped principal diagnoses into 19 categories, as shown in Table 1. Our taxonomic system reflected both clinical considerations about the similarity of diseases and numerical considerations to ensure that no one category was too large or too small for analysis. Patients with missing data on race were excluded from the regression analysis $(n=166)$. No data were missing for any of the other variables, except as outlined below for the Charlson score.

We used the MEDPAR data from the patients' hospital stays in the preceding 270 days to develop a Charlson comorbidity score for every patient. ${ }^{24}$ This score ranges from 0 to a theoretical maximum of 33 and is based on the presence of certain diseases with assigned values. We also developed an adjusted Charlson score, which excluded the patient's primary diagnosis at the time of admission to a hospice, since our intention was to measure and control for the effects of conditions other than the patient's principal diagnosis. There were 1545 patients in the cohort ( 24.0 percent) who were not hospitalized in the 270 days before their admission to a hospice program; it was thus not possible to assign them a Charlson score. We dealt with these missing values by substituting the mean Charlson score for the patient group as a whole and including a dummy variable representing missing data among the explanatory variables in the regression model. ${ }^{25}$ The coefficient for this missing-data variable may be interpreted as the effect of having had no recent hospitalizations.

We developed three measures of the use of resources before admission to the hospice: the number of hospitalizations in the 270 days before enrollment; the total number of hospital days in the 270-day period; and the total number of hospital days in the 30 days before enrollment.

Finally, we developed four variables to describe the hospice providers: the number of years the program had been in operation as a Medicare provider as of 1990 (range, 1 to 8); the number of employees ("large" hospices were those with 30 or more employees); the type of provider ("inpatient," defined as a program run by a hospital or by an inpatient nursing facility, or "outpatient," defined as a program run by a dedicated hospice or by a home health agency); and the type of ownership (for-profit, proprietary vs. nonprofit, voluntary or government).

\section{RESULTS}

\section{Characteristics of Medicare Beneficiaries in Hospice Care}

The mean $( \pm S D)$ age of the patients in the cohort was $76.4 \pm 9.0$ years; 92.4 percent of the patients were white, and 50.0 percent were women. Approximately half the patients in the cohort ( 49.7 percent) were cared for by large hospices; 16.1 percent by forprofit hospices; and 22.8 percent at inpatient hospice programs. Of the patients in the cohort, 80.2 percent had cancer of some type; lung cancer (21.4 percent), colorectal cancer ( 10.5 percent $)$, and prostate cancer (7.4 percent) were the most common diagnoses (Table 1). The patients were very sick; the mean unadjusted score on the Charlson index for the 4906 patients for whom this score could be determined was $5.2 \pm 3.3$, and the mean adjusted Charlson score was $3.8 \pm 3.0$.

In the 270 days before admission to a hospice program, the patients averaged 1.6 \pm 1.7 hospital admissions; only 1545 patients ( 24.0 percent) had no admissions during that 270-day period. The mean total number of hospital days in the 270 days before enrollment in a hospice program was $18.3 \pm 23.3 ; 1296$ (20.0 percent) of the patients spent more than 30 of the 270 days as hospital inpatients. The mean total number of hospital days in the 30 days before enrollment in a hospice program was $11.5 \pm 13.7$. Of the cohort, 1814 patients (28.1 percent) were not hospitalized for any part of the 30 days before entering a hospice program; 2942 patients (45.6 percent) were hospitalized for at least part of the 30 days before enrollment; and 1695 patients (26.3 percent) spent the whole month in the hospital. The median lengths of survival after enrollment in a hospice program for these three groups were 43 days, 32 days, and 26 days, respectively $(\mathrm{P}<0.01$ by the Kruskal-Wallis test of the difference in medians among groups). 
Table 1. Survival According to Diagnosis among 6451 Medicare Beneficiaries Enrolled in Hospice Programs.

\begin{tabular}{|c|c|c|c|c|}
\hline Diagnosis & $\begin{array}{c}\text { No. (\%) } \\
\text { OF Patients }\end{array}$ & $\begin{array}{c}\text { MEDIAN } \\
\text { SuRVIVAL } \\
\text { (DAYS) }\end{array}$ & $\begin{array}{c}\text { PERCENTAGE } \\
\text { WHO DIED } \\
\text { WITHIN } 7 \text { DAYS }\end{array}$ & $\begin{array}{c}\text { Percentage } \\
\text { Who Lived } \\
\text { Longer Than } \\
180 \text { Days }\end{array}$ \\
\hline \multicolumn{5}{|l|}{ Cancer } \\
\hline Leukemia or lymphoma & $291(4.5)$ & 23.0 & 20.6 & 14.1 \\
\hline Urinary tract & $256(4.0)$ & 24.0 & 14.1 & 12.9 \\
\hline Colon or rectum & $678(10.5)$ & 31.0 & 15.8 & 12.4 \\
\hline Pancreas & $289(4.5)$ & 31.0 & 18.3 & 10.0 \\
\hline Female genital tract & $223(3.5)$ & 34.0 & 17.5 & 14.8 \\
\hline Upper gastrointestinal tract & $221(3.4)$ & 34.5 & 13.1 & 9.0 \\
\hline Head or neck & $101(1.6)$ & 38.0 & 17.8 & 13.9 \\
\hline Lung & $1378(21.4)$ & 38.0 & 14.2 & 11.8 \\
\hline Breast & $364(5.6)$ & 43.5 & 13.5 & 9.0 \\
\hline Central nervous system & $141(2.2)$ & 44.0 & 7.1 & 14.2 \\
\hline Prostate & $480(7.4)$ & 46.0 & 14.0 & 13.7 \\
\hline Liver or biliary tract & $205(3.2)$ & 50.0 & 22.4 & 8.8 \\
\hline All other cancers & $548(8.5)$ & 32.5 & 15.1 & 12.0 \\
\hline \multicolumn{5}{|l|}{ Other diseases } \\
\hline Renal failure & $85(1.3)$ & 17.0 & 29.4 & 12.9 \\
\hline Stroke & $142(2.2)$ & 33.0 & 21.1 & 22.5 \\
\hline Congestive heart failure & $316(4.9)$ & 43.5 & 14.2 & 22.5 \\
\hline Dementia & $95(1.5)$ & 74.0 & 9.5 & 34.7 \\
\hline Chronic obstructive pulmonary disease & $200(3.1)$ & 76.5 & 12.0 & 32.0 \\
\hline All other noncancer diseases & $438(6.8)$ & 34.0 & 18.3 & 21.2 \\
\hline Total & $6451(100.0)$ & 36.0 & 15.6 & 14.9 \\
\hline
\end{tabular}

\section{Survival after Enrollment in a Hospice Program}

The median length of survival after enrollment was 36 days (interquartile range, 12 to 97) (Fig. 1). A substantial minority of patients, 15.6 percent, died within 7 days of enrollment, and 28.5 percent died within 14 days. At the other extreme, 14.9 percent lived longer than 180 days, and 8.2 percent lived longer than a year. The patients who lived more than a year after enrollment were more likely than those who died sooner to have one of several diagnoses: cancer of the female genital tract, breast cancer, stroke, congestive heart failure, dementia, and chronic obstructive pulmonary disease.

\section{Disease-Specific Survival}

There was substantial variation in both the median length of survival and in the range of survival times according to diagnosis (Fig. 2 and Table 1). The median length of survival varied from 17 days for patients with renal failure to 77 days for those with chronic obstructive pulmonary disease $(\mathrm{P}<0.001$ by the Kruskal-Wallis test of the difference in medians among diagnostic groups) (Table 1). The interquartile range varied from 39 days for liver or biliary cancer to 349 days for dementia $(\mathrm{P}<0.001$ by Bartlett's test of the difference in the range among diagnoses) (Fig. 2). The proportion of patients who died within a week varied from 7.1 percent for those with cancer of the central nervous system to 29.4 percent for those with renal failure; the proportion of patients who died more than six months after enrollment varied from 8.8 percent for liver or biliary cancer to 34.7 percent for dementia (Table 1).

The variability of the length of survival among patients with different diagnoses persisted after we controlled for measured characteristics of the patients and the hospice providers (Table 2). Specifically, as compared with patients with lung cancer, and with adjustment for other factors, patients with breast cancer had an 18 percent lower risk of death (hence, longer survival after enrollment), those with central nervous system cancer a 17 percent lower risk, those with prostate cancer a 15 percent lower risk, those with congestive heart failure a 24 percent lower risk, those with dementia a 29 percent lower risk, and those with chronic obstructive pulmonary disease a 29 percent lower risk. Conversely, those with liver or biliary cancer had a 24 percent higher risk of death (hence, shorter survival) than those with lung cancer. A joint test of significance for the variables related to the primary diagnosis provides evidence of the importance of the diagnosis in determining the length of survival after enrollment $(\mathrm{P}<0.001)$.

\section{Other Factors Associated with Survival}

Additional findings in the regression analysis were that men had a 10 percent higher risk of death (indicating shorter survival) than women, and whites 


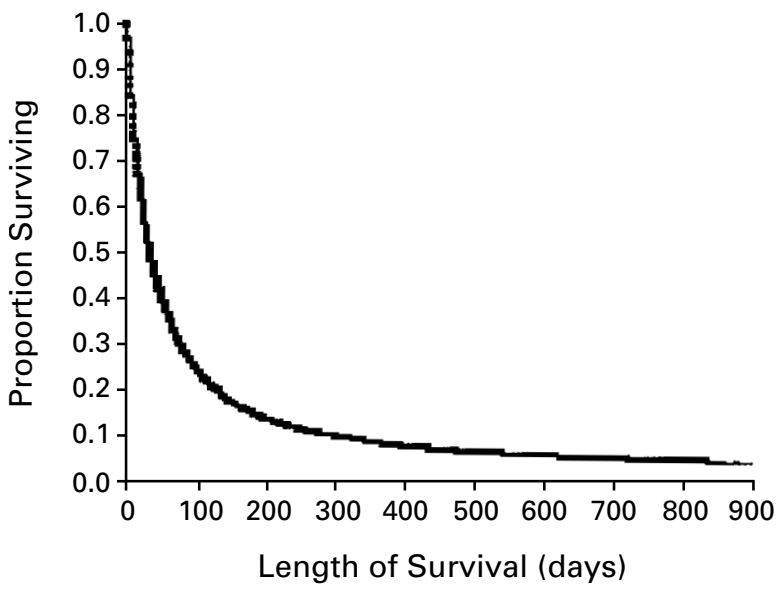

Figure 1. Kaplan-Meier Survival Curve for 6451 Medicare Beneficiaries Enrolled in Hospice Programs in 1990.

Survival was measured from the day of enrollment in the hospice program to the day of death.

had an 11 percent higher risk than nonwhites (Table 2 ). In terms of time, the unadjusted median length of survival was 33.5 days for men as compared with 39 days for women, and 34 days for whites as compared with 38 days for nonwhites. After we controlled for other factors, age was not associated with the length of survival after enrollment in a hospice. Each point on the adjusted Charlson index was associated with a 3 percent higher risk of death. Patients cared for by large hospices had a 23 percent lower risk of death than others, those in forprofit hospices a 10 percent lower risk of death, and those in inpatient facilities a 14 percent higher risk of death. The unadjusted median length of survival was 46 days in large hospices as compared with 28 days in small hospices, 52 days in for-profit hospices as compared with 32 days in not-for-profit hospices, and 39 days in outpatient facilities as compared with 26 days in inpatient facilities.

\section{DISCUSSION}

In our study of survival among Medicare patients enrolled in hospice programs, four facts were evident. First, overall survival was short, with a median of 36 days. Second, there was substantial variation in the length of survival after enrollment; many patients survived for short periods (less than 7 days) and many for long periods (more than 180 days), together accounting for 30.5 percent of all patients. Third, there was substantial variation in both the median survival and the range of survival times according to diagnosis. Fourth, there was substantial variation in survival according to the type of hospice provider, even after adjustment for a number of characteristics of the patients.

Previous studies of single hospices, both in the
United States and abroad, have found median survival times of 11 to 30 days, ${ }^{26-33}$ and those based on data from multiple hospices have found survival times of 25 to 35 days. ${ }^{3,10,34}$ These studies have been limited, however, by their focus on inpatients, by their exclusion of patients with diagnoses other than cancer, or by their incomplete or short follow-up or small or nonrepresentative samples. Moreover, previous studies of survival among patients in hospices either have neglected the role of diagnosis ${ }^{33}$ or have not found a relation between diagnosis and the length of survival after enrollment ${ }^{34}$; some studies, however, have suggested a relation between certain diagnoses and the timing of patients' referral to hospices. ${ }^{29,35}$

The duration of survival after enrollment in a hospice is an important outcome to measure because it is relevant to the quality and cost of care that patients receive at the end of life. Both long and short survival - especially to the extent that the length of survival may be due to avoidably early or late enrollment may have adverse economic consequences for payers and cause needless suffering for patients. ${ }^{3,29,36}$ For example, for many patients, short survival after enrollment in a hospice program may mean that they have made inadequate use of a desirable type of terminal care and that their hospice providers have had inadequate time to learn their needs and develop an optimal plan for care. Short survival might also mean that patients have received costly and possibly unnecessarily aggressive care for an unduly long period before enrollment in the hospice. Although patients may have derived benefit from short stays in hospices in some cases, earlier referral, to the extent that it was possible, might have brought even greater benefits.

The timing of enrollment, an event that is under the control of human decision makers, is the fundamental determinant of the observed duration of survival in hospices. Although patients, families, and the hospice staff members influence decisions about enrollment, ${ }^{7}$ physicians are critical to this process. Physicians act as gatekeepers, initiate the great majority of referrals, and are required to certify that the patient has a life expectancy of less than six months. Consequently, it might be possible to modify the survival curve of patients enrolled in hospices by changing the behavior of patients, physicians, or hospice providers. If patients were enrolled earlier and if efforts were directed to reducing the percentages of patients with especially long or short stays in hospices, it might be possible to improve the use of hospice care from both the individual and the social perspectives.

Our data demonstrate that the majority of patients enrolled in hospice programs under the Medicare hospice benefit, especially those with cancer, are enrolled relatively late in the course of a terminal illness. Several factors may be responsible for this fact. 


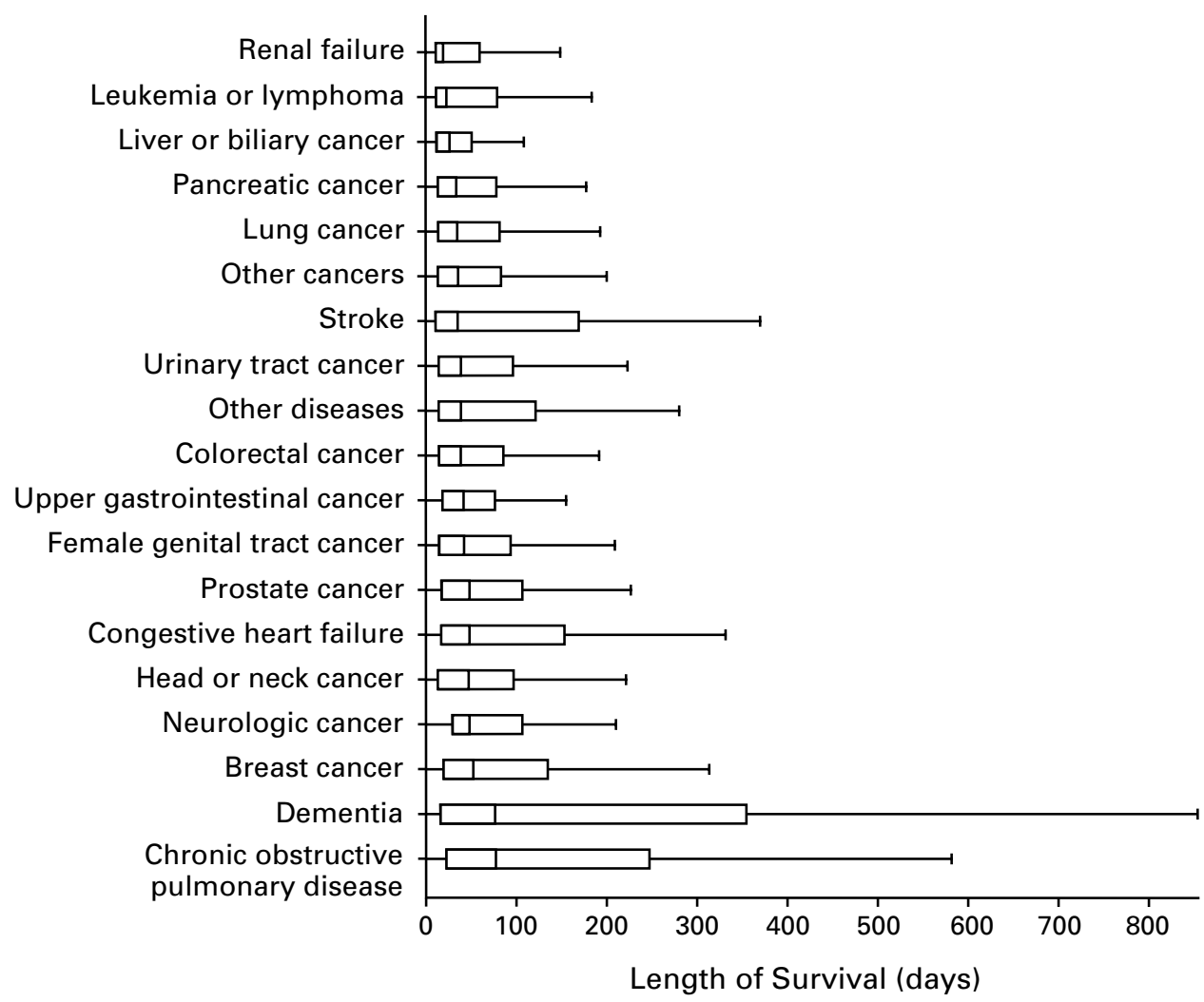

Figure 2. Tukey Box Plots of the Length of Survival According to Diagnosis among 6451 Medicare Beneficiaries Enrolled in Hospice Programs in 1990.

Box plots show the median (center vertical line), interquartile range (the 25th to the 75th percentile [box]), and "whiskers" (whiskers are 1.5 times the interquartile range, spread out from the first and third quartiles, and do not extend beyond the smallest or largest observed value). The diagnostic groups are arranged according to the median length of survival.

For example, patients may resist being told that the illness is terminal, and physicians may want to preserve hope by postponing referral. The difficulty physicians face in making prognoses probably also has a role. Commentators have noted that physicians typically make poor judgments about survival in terminally ill patients; both unduly pessimistic prognoses (with consequent early referral to hospices) and unduly optimistic prognoses (with late referral) may have adverse effects. ${ }^{77-39}$ Unfortunately, few studies have examined the process of prognostication in patients in hospice ${ }^{40,41}$ or hospital ${ }^{42}$ settings.

Current Medicare regulations may inadvertently reinforce the late enrollment of patients by specifying an upper limit to survival - that is, by stating only patients with less than six months to live are to be referred. However, the fact that short survival at hospices is also seen in countries other than the United States, ${ }^{28,31-33}$ where there are different regulations, suggests the importance of more fundamental factors related to how physicians and patients confront terminal illness and make predictions about survival. Nevertheless, alternative prognostic stand- ards, such as requiring that the prognosis be "an average survival of six months" or "a 50 percent probability of death in three months," might minimize the possible contribution of Medicare regulations to late enrollment.

Enrolling patients earlier, especially those otherwise destined to have short stays, might enhance the quality of end-of-life care and also prove cost effective. Although an increase in the median survival due to earlier enrollment would increase the costs to Medicare of hospice care, it might nevertheless be cost saving if expensive in-hospital care were supplanted. Of the total hospital days in the 270 days before enrollment, 63 percent were during the 30 days just before admission to the hospice. Moreover, patients with a large number of inpatient days in the 30 days before enrollment in a hospice tended to have relatively short survival after enrollment, suggesting that earlier referral might indeed substitute hospice care for more expensive hospital care. Further work is required to clarify potential cost savings.

With respect to possible ways to modify the observed survival pattern, attention should also be paid 
Table 2. Risk of Death after EnRollment in Hospice Programs, According to Characteristics of Patients and Providers.*

VARIABLE

RISK RATIO (95\% Cl)

Demographic and clinical characteristics

Male sex

Age (each five-year increment)

White race

Number of recent hospitalizations

Adjusted Charlson comorbidity score

Comorbidity-score dummy

Diagnosis

Leukemia or lymphoma

Urinary tract cancer

Colorectal cancer

Pancreatic cancer

Female genital tract cancer

Upper gastrointestinal cancer

Head or neck cancer

Lung cancer

Breast cancer

Central nervous system cancer

Prostate cancer

Liver or biliary cancer

All other cancers

Renal failure

Stroke

Congestive heart failure

Dementia

Chronic obstructive pulmonary

disease

All other noncancer diseases

$1.10(1.04-1.16) \dagger$

$1.00(1.00-1.00)$

$1.11(1.01-1.23) \dagger$

$1.04(1.02-1.06) \dagger$

$1.03(1.02-1.04) \dagger$

$0.93(0.86-1.00)$

$1.10(0.96-1.26)$

$0.96(0.84-1.11)$

$0.96(0.87-1.06)$

$1.04(0.91-1.19)$

$0.91(0.78-1.06)$

$0.98(0.84-1.13)$

$0.88(0.71-1.09)$

$1.00(-)$

$0.82(0.72-0.93)$

$0.83(0.69-0.99) \dagger$

$0.85(0.76-0.96) \dagger$

$1.24(1.07-1.45) \dagger$

$0.99(0.90-1.10)$

$1.17(0.93-1.49)$

$0.86(0.71-1.04)$

$0.76(0.66-0.87) \dagger$

$0.71(0.56-0.89) \dagger$

$0.71(0.61-0.84) \dagger$

Characteristics of hospice providers

Large size

For-profit status

Inpatient facility

Years in operation

$0.86(0.77-0.97) \dagger$

$0.77(0.72-0.82) \dagger$

$0.90(0.84-0.97) \dagger$

$1.14(1.07-1.21) \dagger$

$1.03(1.01-1.04) \dagger$

*The table shows data from a Cox proportional-hazards regression model giving the risk ratios and 95 percent confidence intervals (CIs) for death. Risk ratios greater than 1.0 imply a higher risk of death than the reference or omitted category and hence a shorter survival time after enrollment; values lower than 1.0 imply a lower risk and thus longer survival. The reference category for diagnosis (defined as having a risk of 1.0) is patients with lung cancer. For all dichotomous variables, the patients with the characteristic were compared with those without it. For the number of hospitalizations, adjusted Charlson comorbidity score, and years in operation, the risk ratio expresses the effect on the risk of death for each one-unit increment in these variables. The comorbidity-score dummy is a variable indicating that the adjusted Charlson score was missing (see the Methods section for details).

$\dagger \mathrm{P}<0.05$.

to the fact that patients in large and for-profit hospices have relatively long survival after enrollment. Because the survival of patients after enrollment is generally short, because evaluating newly admitted patients is expensive, and because payment is made on a per diem basis, these observations suggest that such hospices may encourage the early enrollment of patients as a way to recoup the high up-front costs associated with admission. ${ }^{43}$ Do such hospices have efficient outreach programs or place fewer barriers to enrollment? Do they offer care in such a way that patients, families, and physicians are willing to con- sider earlier enrollment? Or do they inappropriately admit patients they expect to live many months after enrollment? Conversely, do they refuse referrals of patients who are near death? If so, how do they identify such patients?

Our study has several limitations. First, only patients actually enrolled in hospice programs were studied, and hence the timing of enrollment was examined only for such patients. Second, our study sample may not have been representative of all patients receiving hospice care; however, Medicare beneficiaries account for about 80 percent of patients in hospices. Third, data on the performance status of patients were not available, but we did adjust for coexisting conditions and for hospitalization before enrollment. Fourth, using claims data to estimate Charlson scores has certain unavoidable limitations. ${ }^{44,45}$ Fifth, we did not study the duration of illness before enrollment in a hospice. Sixth, we did not measure the use of health care services other than inpatient hospital care, such as prescription medications or home nursing care. Finally, no information was available about the referring physicians or about patients' preferences.

Changes in patterns of enrollment in hospice programs might reduce expenditures for health care while improving the quality of care at the end of life. A change in enrollment patterns, however, would require that physicians, patients, and families accept the provision of hospice care earlier in the course of illness. Our findings thus suggest a need for further investigation of the characteristics of physicians, patients, and hospice providers that are associated with the timing of enrollment in hospice programs. Closer study is needed of the process by which patients, families, physicians, and hospice staff members decide whether and when to enroll a patient in a hospice program. Better understanding of this process may lead to improved access to this humane and cost-effective form of terminal care.

Supported by a National Research Service Award Fellowship from the Agency for Health Care Policy and Research, by the Soros Foundation Project on Death in America Faculty Scholars Program, by the WarrenWhitman-Richardson Fellowship, Harvard Medical School, and the Boettner Institute of Financial Gerontology and the McCabe Fund, University of Pennsylvania.

We are indebted to $\mathrm{Ms}$. Wei Chen for expert programming assistance in linking the data files and to Peter D. Friedmann, M.D., M.P.H., Marshall H. Chin, M.D., M.P.H., and Charles von Gunten, M.D., Ph.D., for their helpful comments on the manuscript.

\section{REFERENCES}

1. Moinpour CM, Polissar L. Factors affecting place of death of hospice and non-hospice cancer patients. Am J Public Health 1989;79:1549-51.

2. Mor V, Hiris J. Determinants of site of death among hospice cancer patients. J Health Soc Behav 1983;24:375-85.

3. Greer DS, Mor V, Morris JN, Sherwood S, Kidder D, Birnbaum H. An alternative in terminal care: results of the National Hospice Study. J Chronic Dis 1986;39:9-26. 
4. Kane RL, Klein SJ, Bernstein L, Rothenberg R, Wales J. Hospice role in alleviating the emotional stress of terminal patients and their families. Med Care 1985;23:189-97.

5. Wallston KA, Burger C, Smith RA, Baugher RJ. Comparing the quality of death for hospice and non-hospice cancer patients. Med Care 1988;26: 177-82.

6. Dawson NJ. Need satisfaction in terminal care settings. Soc Sci Med 1991;32:83-7.

7. Mor V, Greer DS, Kastenbaum R. The hospice experiment. Baltimore John Hopkins University Press, 1988.

8. Kidder D. The effects of hospice coverage on Medicare expenditures. Health Serv Res 1992;27:195-217.

9. Mor V, Kidder D. Cost savings in hospice: final results of the National Hospice Study. Health Serv Res 1985;20:407-22.

10. Hannan EL, O'Donnell JF. An evaluation of hospices in the New York State Hospice Demonstration Program. Inquiry 1984;21:338-48.

11. Spector WD, Mor V. Utilization and charges for terminal cancer patients in Rhode Island. Inquiry 1984;21:328-37.

12. Brooks $\mathrm{CH}$, Smyth-Staruch $\mathrm{K}$. Hospice home care cost savings to third-party insurers. Med Care 1984;22:691-703.

13. Davis FA. Medicare hospice benefit: early program experiences. Health Care Financ Rev 1988;9(4):99-111

14. Bulkin W, Lukashok H. Rx for dying: the case for hospice. N Engl J Med 1988;318:376-8.

15. National Hospice Organization. 1992 Stats show continued growth in programs and patients. NHO Newsline 1993;3(16):1-2

16. Strahan GW. An overview of home health and hospice care patients: preliminary data from the 1993 National Home and Hospice Care Survey. Advance data from vital and health statistics. No. 256. Hyattsville, Md.: National Center for Health Statistics, 1994. (DHHS publication no. (PHS) 94-1250.)

17. Social Security Act 1861 (dd)(3)(A)

18. Lynn J, Teno JM, Harrell FE Jr. Accurate prognostications of death: opportunities and challenges for clinicians. West J Med 1995;163:250-7. 19. Charlson ME, Pompei P, Ales KL, MacKenzie CR. A new method of classifying prognostic comorbidity in longitudinal studies: development and validation. J Chronic Dis 1987;40:373-83.

20. Kaplan EL, Meier P. Nonparametric estimation from incomplete observations. J Am Stat Assoc 1958;53:457-81.

21. Tukey JW. Exploratory data analysis. Reading, Mass.: Addison-Wesley, 1977.

22. Teachman JD, Hayward MD. Interpreting hazard rate models. Sociol Methods Res 1993;21:340-71.

23. Department of Health and Human Services. The international classification of diseases, 9th rev., clinical modification: ICD-9-CM. Vol. 1. Dis eases: tabular list. Washington, D.C.: Government Printing Office, 1980. (DHHS publication no. (PHS) 80-1260.

24. Deyo RA, Cherkin DC, Ciol MA. Adapting a clinical comorbidity index for use with ICD-9-CM administrative databases. J Clin Epidemiol 1992;45:613-9.

25. Cohen J, Cohen P. Applied multiple regression/correlation analysis for the behavioral sciences. Hillsdale, N.J.: Lawrence Erlbaum, 1975.

26. Forster LE, Lynn J. The use of physiologic measures and demographic variables to predict longevity among inpatient hospice applicants. Am J Hospice Care 1989;6:31-4.

27. Infeld DL, Crum GE, Koshuta MA. Characteristics of patients in a long-term care hospice setting. Hospice J 1990;6(4):81-104.

28. Allard P, Dionne A, Potvin D. Factors associated with length of survival among 1081 terminally ill cancer patients. J Palliat Care 1995;11(3):20-4.

29. Christakis NA. Timing of referral of terminally ill patients to an outpatient hospice. J Gen Intern Med 1994;9:314-20.

30. Schonwetter RS, Teasdale TA, Storey P, Luchi RJ. Estimation of survival time in terminal cancer patients: an impedance to hospice admissions? Hospice J 1990;6(4):65-79.

31. Rosenthal MA, Gebski VJ, Kefford RF, Stuart-Harris RC. Prediction of life-expectancy in hospice patients: identification of novel prognostic factors. Palliat Med 1993;7:199-204.

32. Evans C, McCarthy M. Referral and survival of patients accepted by a terminal care support team. J Epidemiol Community Health 1984;38:310 4.

33. Bruera E, Miller MJ, Kuehn N, MacEachern T, Hanson J. Estimate of survival of patients admitted to a palliative care unit: a prospective study. J Pain Symptom Manage 1992;7:82-6.

34. Reuben DB, Mor V, Hiris J. Clinical symptoms and length of survival in patients with terminal cancer. Arch Intern Med 1988;148:1586-91.

35. Hyman RB, Bulkin W. Physician reported incentives and disincentives for referring patients to hospice. Hospice J 1990;6(4):39-64.

36. Office of Research and Demonstrations. Report to Congress: highcost hospice care. Baltimore: Health Care Financing Administration, 1994 (HCFA publication no. 03360.)
37. Pearlman RA. Inaccurate predictions of life expectancy: dilemmas and opportunities. Arch Intern Med 1988;148:2537-8.

38. Brody H, Lynn J. The physician's responsibility under the new Medicare reimbursement for hospice care. N Engl J Med 1984;310:920-2.

39. Potter JF. A challenge for the hospice movement. N Engl J Med 1980; 302:53-5.

40. Forster LE, Lynn J. Predicting life span for applicants to inpatient hospice. Arch Intern Med 1988;148:2540-3

41. Parkes CM. Accuracy of predictions of survival in later stages of cancer. BMJ 1972;2:29-31.

42. Knaus WA, Harrell FE Jr, Lynn J, et al. The SUPPORT prognostic model: objective estimates of survival for seriously ill hospitalized adults: Study to Understand Prognoses and Preferences for Outcomes and Risks of Treatments. Ann Intern Med 1995;122:191-203.

43. Carney K, Burns N, Brobst B. Hospice costs and Medicare reimbursement: an application of break-even analysis. Nurs Econ 1989;7:41-7. 44. Iezzoni LI, Foley SM, Daley J, Hughes J, Fisher ES, Heeren T. Comorbidities, complications, and coding bias: does the number of diagnosis codes matter in predicting in-hospital mortality? JAMA 1992;267:2197203.

45. Romano PS, Mark DH. Bias in the coding of hospital discharge data and its implications for quality assessment. Med Care 1994;32:81-90. 
CORRECTION

Survival of Medicare Patients after Enrollment in Hospice Programs

Survival of Medicare Patients after Enrollment in Hospice Programs . On page 174, in Table 1, several of the median survival values were incorrect. The correct values are as follows: urinary tract, 34 days; colon or rectum, 34.5 days; female genital tract, 38 days; upper gastrointestinal tract, 38 days; head or neck, 44 days; lung, 31 days; breast, 50 days; central nervous system, 46 days; prostate, 43.5 days; and liver or biliary tract, 24 days. 